\title{
A NEXT-GENERATION OPEN-SOURCE TOOL FOR EARTHQUAKE LOSS ESTIMATION
}

\author{
S. MOLINA-PALACIOS ${ }^{1}$, D. H. LANG ${ }^{2}$, A. MESLEM ${ }^{2}$, C. D. LINDHOLM ${ }^{2} \&$ N. AGEA-MEDINA ${ }^{1}$ \\ ${ }^{1}$ Dpto. Ciencias de la Tierra y del Medio Ambiente, Universidad de Alicante, Spain. \\ ${ }^{2}$ NORSAR, Department Earthquake Hazard and Risk, Kjeller, Norway.
}

\begin{abstract}
Earthquake loss estimation (ELE), generally also referred to as earthquake risk assessment, is a comparably young research discipline which, at first, relied on empirical observations based on a macroseismic intensity scale. Later, with the advent of methodologies and procedures that are based on theoretical simulation in estimating physical damage under earthquake loading, the analytical approach for ELE was formulated. The open-source software SELENA, which is a joint development of NORSAR (Norway) and the University of Alicante (Spain), is undergoing a constant development. One of the more recent features being included is the possibility to address topographic amplification of seismic ground motion. Additionally, SELENA has been adapted by including various methods for the analytical computation of structural damage and loss. SELENA now offers complete flexibility in the use of different types of fragility curves based on various ground motion intensity parameters (e.g. PGA, Sa, Sd), which has been suggested by many recently released guidelines (e.g. FEMA P-58, GEM-ASV, SYNER-G, HAZUS$\mathrm{MH}$ ). Besides, under the framework of the ongoing Horizon 2020 LIQUEFACT project, SELENA is extended in order to allow the consideration of liquefaction-induced ground displacements and respective structural damage.

In general, software tools for ELE are particularly useful in two different settings, i.e., for disaster management and (re)insurance purposes. Both sectors pose very different demands on ELE studies: while the (re)insurance sector is foremost interested in the direct and indirect economic losses caused by an earthquake to its insured physical assets, those institutions (often governmental and nongovernmental organizations) in charge of disaster emergency management and response are more interested in reliable estimates on human losses and the potential short- and long-term social consequences. Being aware about these peculiar differences between software tools for disaster management and insurance applications, NORSAR/UA thereby offers two in its core similar software tools, i.e., the opensource software SELENA and the proprietary software PML (Probable Maximum Loss) which is actively used by the insurance association in Chile (South America) since 2011.
\end{abstract}

Keywords: Analytical methods, damage and loss, earthquake loss estimation, SELENA

\section{INTRODUCTION}

Earthquake loss estimation (ELE), generally also referred to as earthquake risk assessment, is a comparably young research discipline which somehow evolved from earthquake hazard assessment after the first studies were published in the late 1960s. Some of the first earthquake loss estimation studies were performed in the early 1970s following the 1971 San Fernando earthquake, and initially they purely relied on empirical observations based on a macroseismic intensity scale. These studies put a heavy emphasis on loss of life, injuries, and the ability to provide emergency health care. Later, with the advent of methodologies and procedures that are based on theoretical simulation in estimating physical damage under earthquake loading, the analytical approach for ELE was formulated. However, its breakthrough came first when FEMA released the first version of HAZUS in 1992 [1, 2]. HAZUS, which was then published in 2001 [3], 2002 [4] and 2003 [5], is a methodological software framework which provides a powerful technique for developing earthquake loss estimates. This framework can be used to anticipate the possible nature of an earthquake disaster and the scope of the emergency response needed to cope with an earthquake disaster, i.e., the 
development of plans for recovery and reconstruction following the event, and the mitigation of its possible consequences of earthquakes.

The following years can be described as the high period of ELE which resulted in numerous risk studies being conducted in many parts of the world, and methodologies and software tools both being developed and enhanced. Nowadays, a large variety of proprietary, free or opensource tools for ELE computation are available. Under the umbrella of the International Centre for Geohazards (ICG), NORSAR (Norway), in collaboration with the University of Alicante (Spain) started the development of an open-source seismic risk estimation tool in 2004 [6] which was later named SELENA (Seismic Loss Estimation using a Logic Tree Approach) [7, 8]. SELENA is coded in Matlab and also available as a compiled stand-alone version. In contrast to many other tools, SELENA is independent of any Geographic Information System (GIS). The user will supply built area or number of buildings disaggregated by different model building typologies, earthquake sources, empirical ground-motion prediction equations (GMPE), soil maps, topographic features and corresponding ground-motion amplification factors, capacity curves and fragility functions corresponding to each of the model building types and finally cost models for building repair or replacement. SELENA will compute, for a given intensity measure (or level of ground motion), the probability of structural damage in each one of the four damage states (slight, moderate, extensive, and complete) for the given building types. This probability is subsequently used with the built area or the number of buildings to express the results in terms of damaged area (square meters) or number of damaged buildings. Finally, using a simplified economic model, the damage is converted to economic losses in the respective input currency and human casualties, in terms of different injury types, are computed. Optionally, mean damage ratios (MDR), the amount of debris resulting from the shaking damage to buildings and the total number of uninhabitable buildings and displaced households can also be computed. The main innovation of this tool is the implementation of the computation under a logic tree scheme, allowing the consideration of epistemic uncertainties related to the different input parameters to be properly included, and the final results are provided with corresponding confidence levels.

The strength of SELENA comes not only from the use of a transparent coding, the ease of preparing input files for any region in the world but also from the availability of the NORSAR-UA consortium in preparing user-specific software versions, if required. These can be adapted to the users' requirements and applications. Since its first release, SELENA has been successfully applied to a multitude of testbeds worldwide (Fig. 1), e.g., Naples [7], Bucharest [9], the

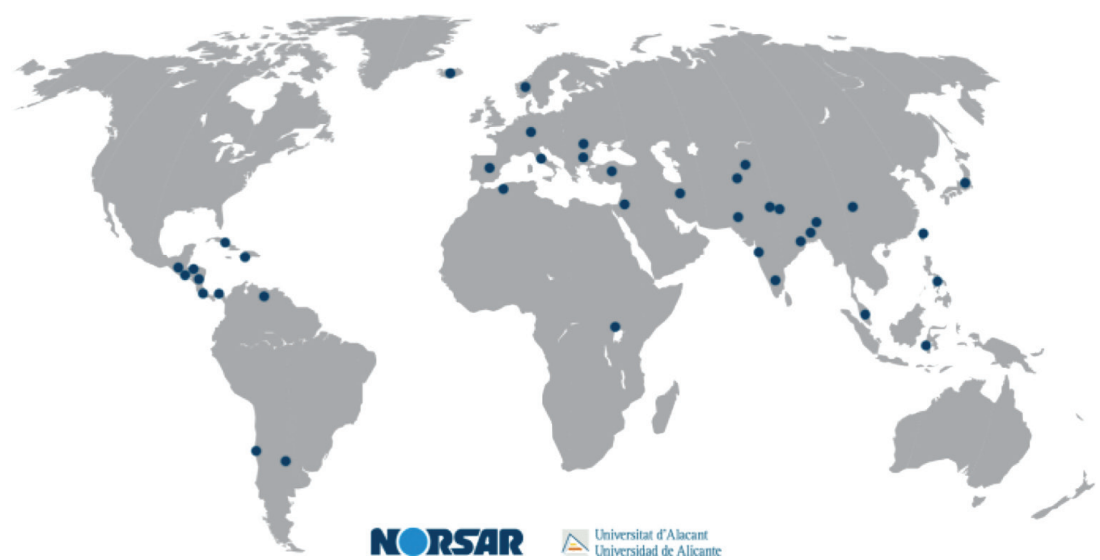

Figure 1: Map distribution of the different countries/cities where SELENA has been applied. 
Romanian-Bulgarian border region [10], Dehradun and Mussoorie (India) [11, 12], Haiti [13, 14], amongst others.

\section{THE SELENA METHODOLOGY}

The implemented methodology has been developed for a population of buildings and cannot be used to estimate the damage or losses associated to individual buildings unless a detailed finite element analysis that considers the peculiarities of an individual building is conducted. Further, the capacity curves and fragility functions used for different building typologies represent 'mean' curves for all buildings that belong to the respective building typology. As such, the results of SELENA are meaningful as long as they are used to estimate the damage and associated losses for a population of buildings. SELENA, like most other risk estimation software tools, considers the minimum geographical unit (geounit), i.e., the census tract, as the smallest area unit. In practice, this unit is related to building blocks or smaller city districts. The decision on the extent of each geographical unit has to be made considering different aspects such as having equal soil conditions, constant surface topography or a homogeneous level of building quality within the demarcated area. The main basis information of any ELE study consists in the building inventory database, which can sometimes be provided, e.g. by local agencies or governmental institutions. In any case, a thorough investigation of the local building stock by walk-down surveys and on-site inspections should be conducted in order to allow a representative classification of the prevalent building typologies. The building inventory database should contain a maximum of details about building materials, structural system, built area, floors of the building, height, foundations, seismic regulations used in the construction, use of the building, number of occupants, year of construction, etc. The building information is classified according to building type in each one of the geographical units which form the region under investigation. Ideally, the classification of the building type should be done following a user-defined classification scheme being most representative for the available building stock. This part of the database compilation represents the most critical phase in order to come up with accurate damage and loss estimates. Alternatively, the classification of building typologies can also be done according to existing taxonomies taken from literature, i.e., HAZUS [5], PAGER [15], GEM [16], SYNERGY [17].

\subsection{Provision of seismic demand}

A key point in any seismic risk assessment is the provision of the seismic ground motion (level and spectral characteristics of earthquake shaking). In order to carry out a seismic damage and loss assessment with SELENA, the user can provide seismic ground-motion estimates on three different ways: a) provision of spectral ordinates (taken out from probabilistic shaking maps) for each geographical unit (herein referred to as 'probabilistic' analysis even though the computation is still of deterministic character); b) definition of deterministic earthquake scenarios (e.g., historical or user-defined events) in combination with appropriate ground-motion prediction equations (GMPEs) in order to compute the spectral ordinates in each geographical unit (deterministic analysis); and c) provision of recorded ground-motion amplitudes at the locations of seismic (strong-motion) recording stations (analysis with real-time data).

In previous versions, spectral acceleration values had to be provided at three spectral periods, i.e., $\mathrm{T}=0.01 \mathrm{~s}$ (referring to peak ground acceleration, PGA), $\mathrm{T}=0.3 \mathrm{~s}(\mathrm{Sa} 0.3)$, and $\mathrm{T}=1.0 \mathrm{~s}$ (Sa1.0), in order to describe the elastic design spectrum following the provisions of the International Building Code IBC-2006 [18]. Most other international seismic design codes 
(e.g. EN 1998, [19]) define the shape of the design spectrum such that only a single design acceleration value, generally PGA, is required to scale the amplitudes of the spectrum. Starting with SELENA v6.0, a site-specific elastic response spectrum can also be used to define the ground motion. If this option is selected, and either the probabilistic or real-time analysis is chosen, spectral acceleration values at nine different periods, i.e., $\mathrm{T}=0.01 \mathrm{~s}(\mathrm{PGA}), 0.10 \mathrm{~s}, 0.20 \mathrm{~s}, 0.30 \mathrm{~s}$, $0.50 \mathrm{~s}, 0.75 \mathrm{~s}, 1.00 \mathrm{~s}, 1.50 \mathrm{~s}$, and $2.00 \mathrm{~s}$, have to be provided. In case of the deterministic analysis, SELENA will use all the spectral periods defined in the respective GMPE in order to describe the response spectrum.

\subsection{Soil-dependent seismic demand - amplification of ground motion}

In case of the presence of sedimentary soil materials at a site, the seismic ground motion at the ground surface is modified both in amplitude and frequency content. SELENA can use soildependent GMPEs or the respective amplification factors and/or corner periods, which basically describe the shape of the design spectra for the different soil classes specified by the corresponding code provisions. Currently, the procedures of IBC-2006 [18], EN 1998 [19], Indian standard IS 1893 [20], Cuban code NC 46 [21] and site-specific elastic response spectrum are incorporated. Furthermore, upcoming SELENA versions will not only include more of these international code provisions but also consider the use of natural ground motion records in order to account for recordto-record variability and hence offer more flexibility to the user.

\subsection{Surface topography-dependent seismic demand - amplification of ground motion}

A major shortcoming of the current generation of analytical ELE software tools is the fact that the contribution of surface topography to the ground motion characteristics is not considered by any of the existing tools; hence applying these tools in hilly regions represents a significant simplification. To address these effects in ELE, the site-specific geometry and subsoil conditions of the sites where the various building assets are located have to be properly assessed and described. In addition to a more complex definition of the seismic ground motion, buildings located at slopes are generally characterized by strong irregularities in plan, elevation and foundation design. These features lead to a complex structural behaviour, which cannot be addressed by nonlinear static-based procedures.

In a newly developed version of SELENA, the conduct of ELE for hilly regions is allowed through the implementation of a user-selectable analysis procedure addressing topographical amplification by taking into consideration the topographic amplification factors given by EN 1998 [19], Italian building code ICMS [22] or a period-dependent topographic amplification relationship recently developed [23].

\subsection{Liquefaction demand and structural performance}

Liquefaction demand expresses the liquefaction-induced ground deformations in horizontal (lateral spreading) and/or vertical direction (settlements) at the site of a structure or infrastructure facility. The method to be implemented for the assessment of liquefaction demand comprises three main steps:

- Evaluation of the site-specific liquefaction susceptibility that defines the tendency of the various geomaterials at a given site to undergo a severe loss of shear strength due to the pore water pressure build-up caused by earthquake ground shaking. 
- Estimation of liquefaction probability, which defines the likelihood of experiencing liquefaction at a specific location given a certain amplitude and duration of ground shaking, as well as the availability of a certain ground water depth.

- Evaluation of the various modes/mechanisms of permanent ground displacement beneath a structure or infrastructure facility. These modes of liquefaction-induced ground deformations/displacements can be divided into two broad categories:

a) Lateral spreading (ground surface deformation) in which the ground is deformed in horizontal direction. This deformation can result in considerable damage to overlying structures. Consequently, liquefaction-induced lateral spreading has been taken into consideration in the available design codes;

b) Ground settlement deformation which is caused by the change in volumetric strain as pore water pressures dissipate after liquefaction has taken place.

The evaluation of building damage states and its overall performance to the various modes of liquefaction-induced ground deformation is essentially associated with a factor, i.e., the foundation system design (in addition to the structural system and member properties).

In general, structures or infrastructure facilities that are vulnerable to liquefaction-induced ground deformation are those with shallow foundations. In this context, the distinction will be whether the foundation is rigid or flexible.

- Structures/infrastructures on foundations that have sufficient relative stiffness, compared to soft underlying soils, and experiencing either uniform or differential movements (i.e., uniform/differential lateral spreading or uniform/differential vertical settlements), may behave as rigid bodies with no or minor damage to the structural elements.

- In case of structures/infrastructures on flexible (i.e., unrestrained) foundations, columns and walls can move independently (either under lateral spreading or vertical settlements) and thus differentially, and hence damage occurs locally in the structural elements. It is also possible to observe rigid body damage.

\subsection{Damage probability computation.}

Currently, the analytical method for seismic risk estimation implemented in SELENA can obtain the structural damage following three different approaches that are chosen by the user in the input files. The user can select: a) The spectral displacement-based damage estimation approach which was the existing approach in the previous SELENA versions (Fig. 2); b) The spectral acceleration-based damage estimation in which each model building type is assigned a natural period $\left(\mathrm{T}_{1}\right)$ and the structural damage is obtained by interrogating a spectral acceleration versus damage probability fragility curve using the spectral acceleration value $\mathrm{Sa}\left(\mathrm{T}_{1}\right)$; and c) The PGA-based damage estimation approach in which, once the PGA is obtained for each site, this value is used to interrogate the PGA-damage probability curves in order to obtain the corresponding damage probabilities (Fig. 3).

Additionally, in the case of the spectral displacement-based seismic risk approach, the initial performance point calculation method implemented in SELENA was the conventional capacity-spectrum method (CSM). Later, the CSM was replaced with its successor, i.e., the MADRS method, as well as the displacement coefficient method (DCM) provided in FEMA356 [24] with the improvements proposed in FEMA-440 [25], which is referred henceforth as Improved Displacement Coefficient Method (I-DCM). Since more recently, SELENA can also obtain the performance point using the N2 Method for a bilinear elastoplastic form of the 


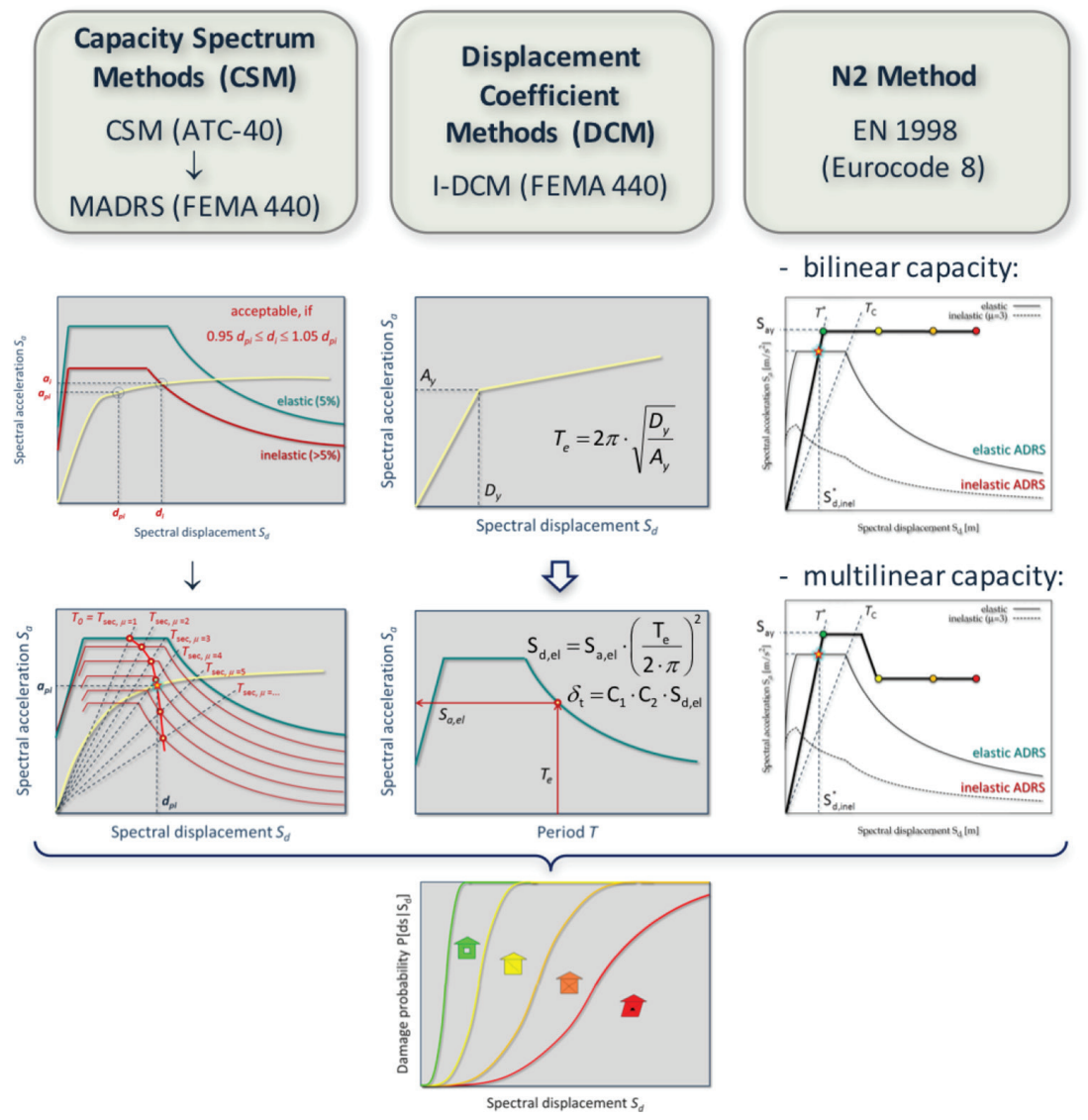

Figure 2: The spectral displacement-based approach implemented in SELENA for structural damage estimation.

capacity curve, based on earlier work of Fajfar [26] and recommended by EN1998 [19] as well as the N2 Method for a multilinear elastoplastic form of the capacity curve, based on earlier work of Dolsek and Fajfar [27].

The final damage results are given as absolute estimates (number of buildings or number of building floor area) of the respective damaged building type, so that users are able to present and further process these results using a spreadsheet program (e.g. MS Excel, OpenOffice, etc.) or any other tools or applications in any desired format (e.g., as percentage of built area $\left[\mathrm{m}^{2}\right]$ normalized by the total built area in each geographical unit or by the total built area in the studied region, i.e., summed over all geographical units).

\subsection{Running SELENA}

SELENA can be downloaded free of charge from the UA web page: http://personal.ua.es/es/ sergio-molina/selena-rise.html or the NORSAR web page: http://www.norsar.no. The software contains all the source code (required when running the software under Matlab), an example of input files and some examples of output files (several folders with different results according to the computation method chosen) as well as the technical user manual. 

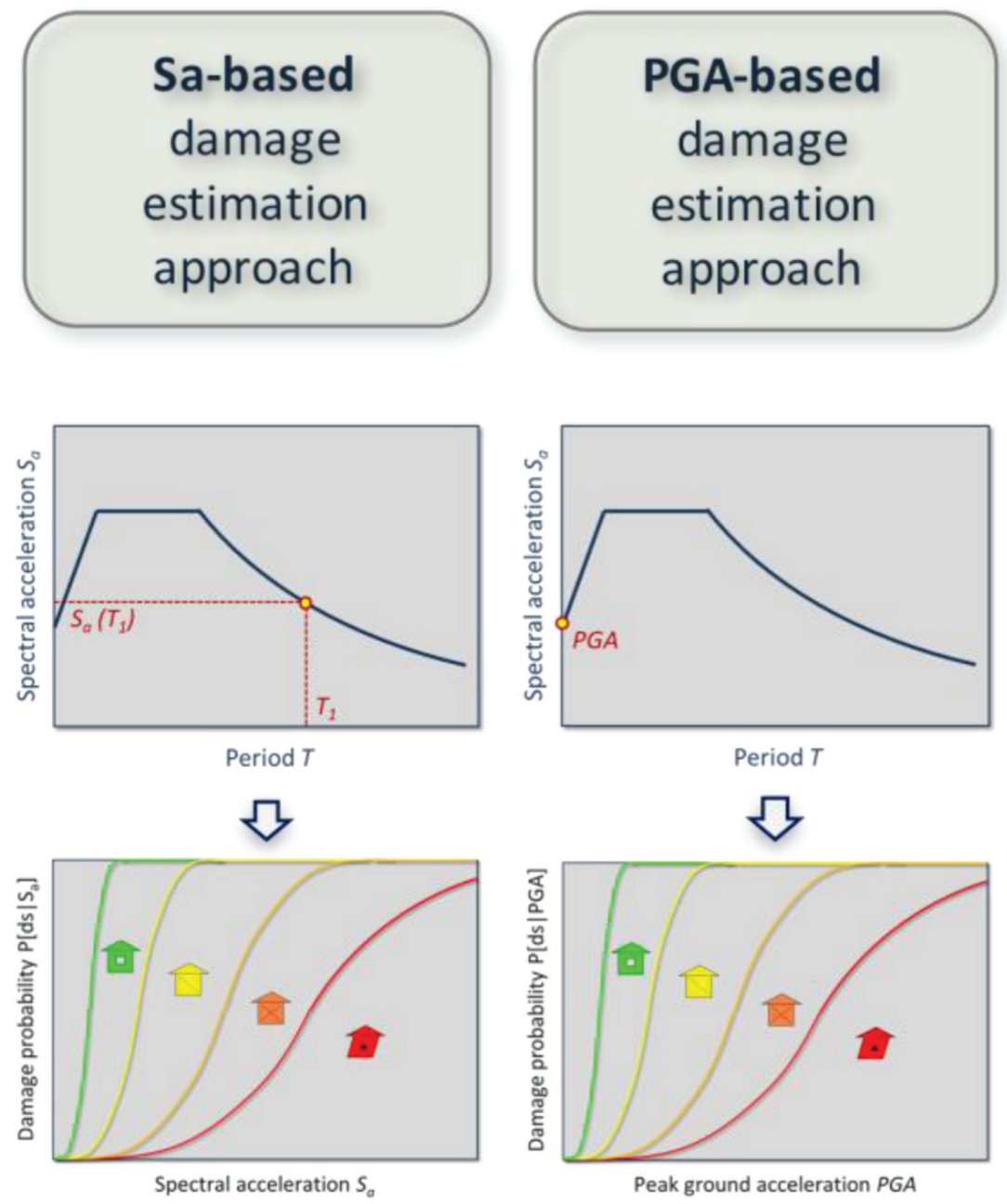

Figure 3: The spectral acceleration-based and PGA-based approach implemented in SELENA for structural damage estimation.

SELENA can be executed under Matlab or as a stand-alone executable using the command window in Windows or the Terminal under Mac OS X. Independently of the operating system, the user should prepare all the required input files into a user-defined folder. The input files need to be prepared in ASCII-format and provided as plain text files (*.txt). A detailed explanation about the formats of all the needed files is given in the user manual. Next, SELENA has to be executed within that folder according to the formats and orders given in the user-manual; i.e., selena d (deterministic earthquake scenario); selena p (probabilistic seismic hazard scenario); selena r ("real-time" ground motion scenario).

Figure 4 shows a flowchart of the current version of SELENA where all required input files and corresponding output files can be seen. 


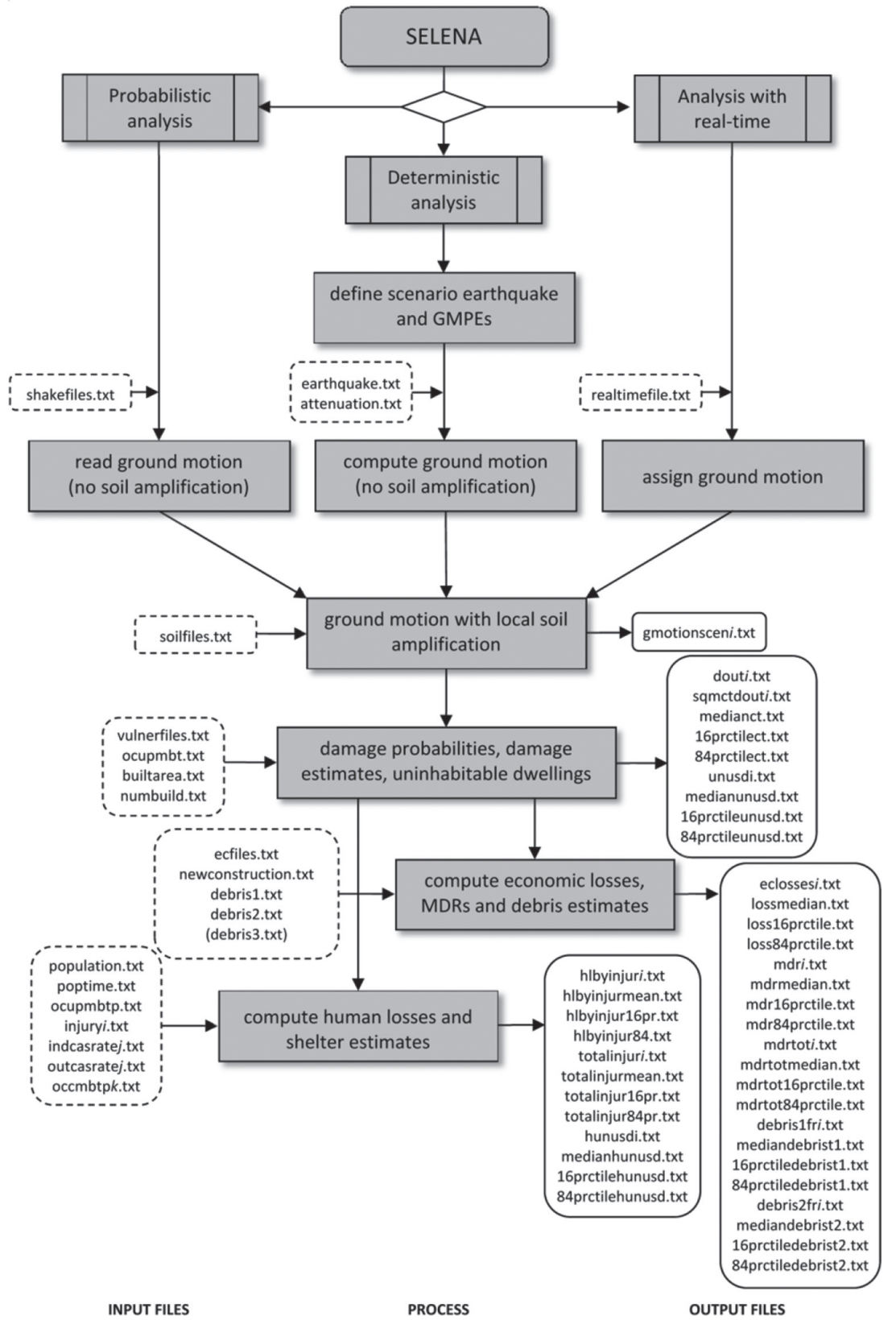

Figure 4: SELENA flowchart.

2.7 Dealing with uncertainties

Currently, SELENA computes median values as well as the $16 \%$ and $84 \%$ fractiles of the seismic risk results. This is done by means of a logic tree methodology in which the different branches of the tree can be weighted so that at the end of the computation, the risk results are 


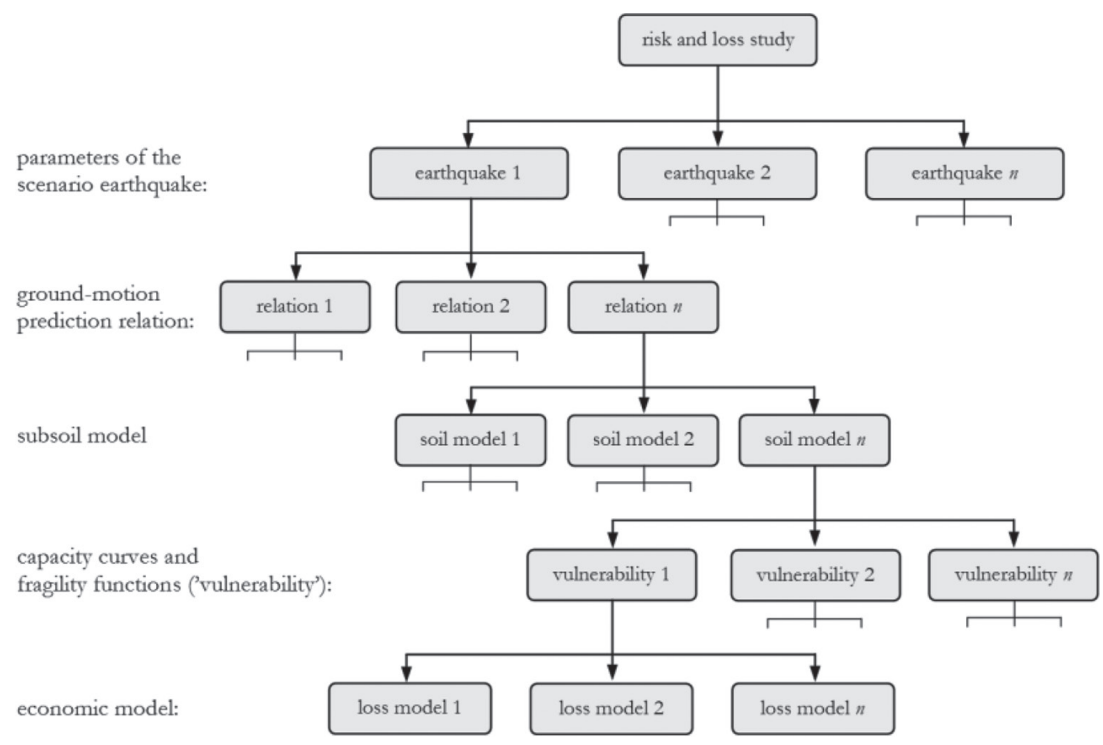

Figure 5: Logic tree structure. Each branch will be weighted in order to compute the expected values and confidence levels.

multiplied by their corresponding weights and then are fitted to a normal distribution in order to obtain the median values as well as its fractiles.

The single branches of the logic tree (Fig. 5) currently represent the epistemic uncertainties of the individual input components: i.e., earthquake source parameters, ground motion prediction equations, soil types, vulnerability curves, and economic values of the built area in case of a deterministic analysis, or ground shaking probabilistic maps, soil types, vulnerability curves, and economic values of the built area in case of a probabilistic analysis. In Fig. 6, we show an example of damage results following five branches of a logic tree and the mean structural damage for a given model building type.

\section{CONCLUSIONS}

The herein described Matlab-based tool SELENA can be used to provide damage results, economic and social losses for the general building stock and population of a city or country on the level of minimum geographical units (i.e., geounit or census tract). The level of resolution of the damage and loss predictions basically depends on the size of the geographical units which can be defined by the user. Both, the Matlab scripts and the ASCII input files are fully transparent allowing the user to apply own modifications and adjustments. Furthermore, it was tried to include as many comments as possible into the code such that the user can go through the scripts and easily change them if necessary.

It should be noticed that the presented tool for seismic risk and loss assessment SELENA is an ongoing development. Therefore, with any new development, SELENA will increase its capability to improve the understanding of the seismic risk in the studied area, to evaluate the effectiveness of different mitigation strategies by measuring risk and their uncertainties before and after they are implemented, to compare the seismic risk with other natural risk using annualized earthquake losses (AEL), and finally to help the insurance and re-insurance decisions by means of Probable Maximum Losses and loss exceedance curves. 


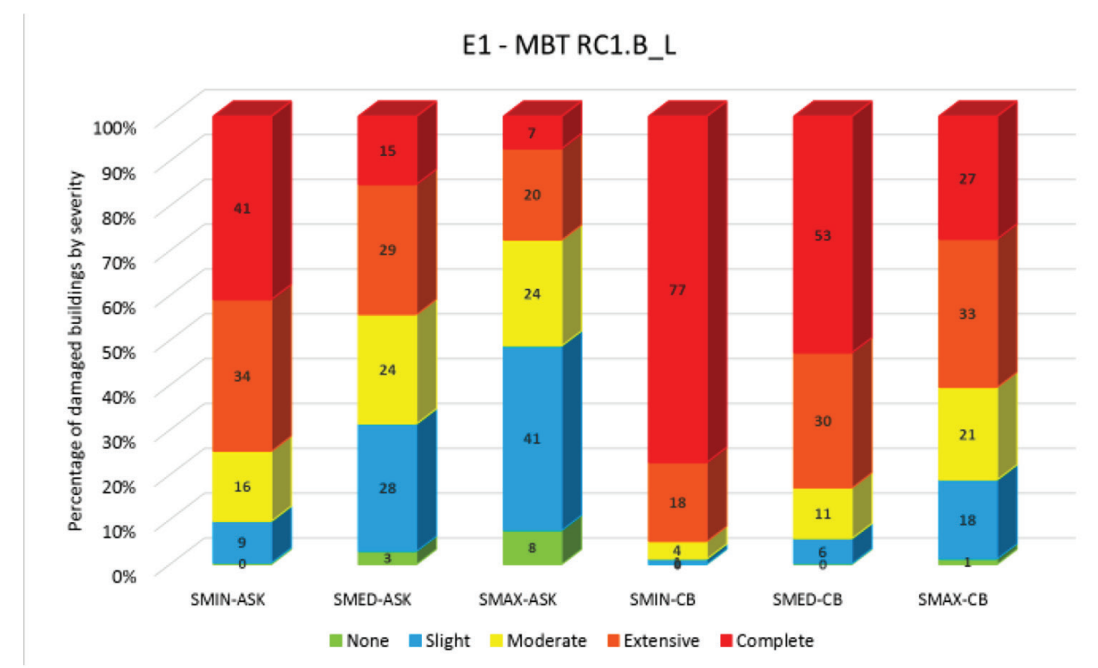

(a)

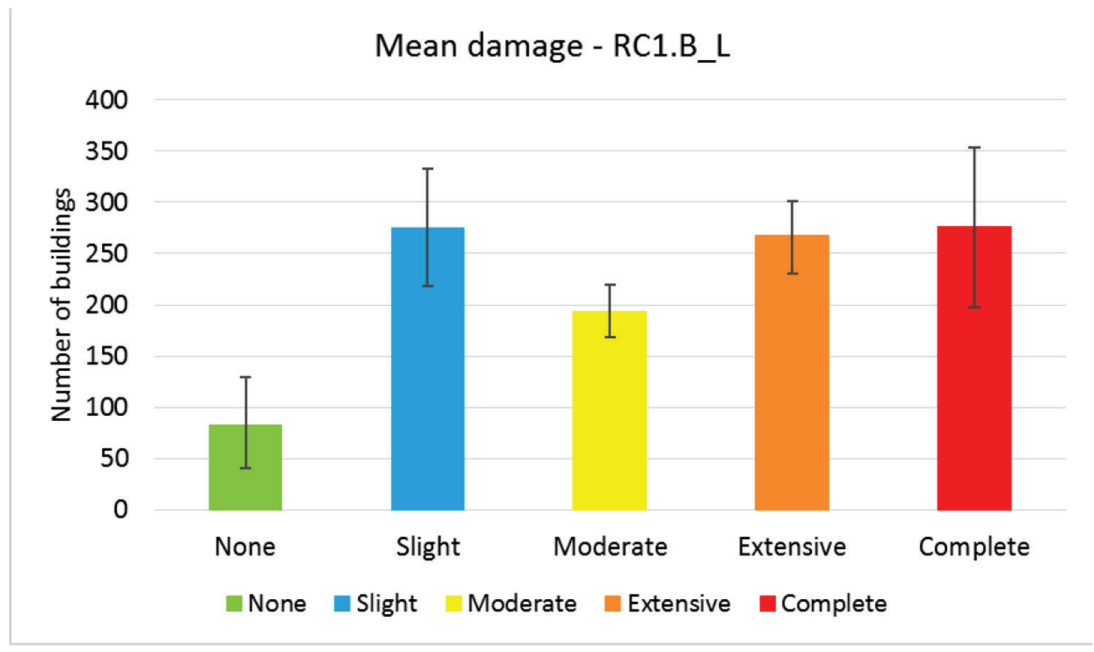

(b)

Figure 6: a) Percentage of damaged building following six branches of a given logic tree (each branch represents a combination of soil conditions and ground motion prediction equation). b) Mean value (expressed as number of damaged buildings).

\section{ACKNOWLEDGEMENTS}

The present research has been benefited from funding of NORSAR and the Univ. Alicante through research contracts (NORSAR1-14A, NORSAR1-08I), the funding of the Ministerio de Economía, Industria y Competitividad (CGL2016-77688-R) and the Generalitat Valenciana (BEST/2012/173 and AICO/2016/098). The development and implementation of the liquefaction risk assessment methodology is done under the LIQUEFACT project funded by the European Union's Horizon 2020 research and innovation programme under grant agreement (No. 700748). 


\section{REFERENCES}

[1] Kircher, C.A., Nassar, A.A., Kustu, O., \& Holmes, W.T., Development of building damage functions for earthquake loss estimation. Earthquake Spectra, 13(4), pp. 663-682, 1997. https://doi.org/10.1193/1.1585974

[2] Whitman, R.V., Anagnos, T., Kircher, C.A., Lagorio, H.J., Lawson, R.S. \& Schneider, P., Development of a national earthquake loss estimation methodology. Earthquake Spectra, 13(4), pp. 643-661, 1997. https://doi.org/10.1193/1.1585973

[3] Federal Emergency Management Agency-FEMA, HAZUS99-SRI estimated annualized earthquake losses for the United States (FEMA 366), Report of the Federal Emergency Management Agency, Washington, DC, United States, 2001.

[4] Federal Emergency Management Agency-FEMA, HAZUS99-SR2 (Service Release 2). Technical Manual, Federal Emergency Management Agency (FEMA) and National Institute of Building Sciences (NIBS), Washington, DC, 2002.

[5] Federal Emergency Management Agency FEMA, HAZUS-MH. Multi-hazard Loss Estimation Methodology, Technical manual., Washington DC, USA, 2003.

[6] Molina, S. \& Lindholm, C.D., A logic tree extension of the capacity spectrum method developed to estimate seismic risk in Oslo, Norway. Journal of Earthquake Engineering, 9(6), pp. 877-897, 2005. https://doi.org/10.1080/13632460509350570

[7] Lang, D.H., Molina, S. \& Lindholm C.D., Towards near-real-time damage estimation using a CSM-based tool for seismic risk assessment. Journal of Earthquake Engineering, 12(2), pp. 199-210, 2008. https://doi.org/10.1080/13632460802014055

[8] Molina, S., Lang, D.H. \& Lindholm, C.D., SELENA - An open-source tool for seismic risk and loss assessment using a logic tree computation procedure. Computers \& Geosciences, 36(3), pp. 257-269, 2010. https://doi.org/10.1016/j.cageo.2009.07.006

[9] Lang, D., Molina-Palacios, S., Lindholm, C. \& Balan, S., Deterministic earthquake damage and loss assessment for the city of Bucharest, Romania. Journal of Seismology, 16(1), pp. 67-88, 2012. https://doi.org/10.1007/s10950-011-9250-y

[10] Erduran, E., Lang, D.H, Lindholm, C., Toma-Danila, D., Balan, S.F., Ionescu, V., Aldea, A., Vacareanu, R. \& Neagu, C., Real-Time earthquake damage assessment in the Romanian-Bulgarian border region, Presented at 15th WCEE, Lisboa, pp. 1-10, 2012.

[11] Lang, D.H., Singh, Y. \& Prasad, J.S.R., Comparing empirical and analytical estimates of earthquake loss assessment studies for the city of Dehradun, India. Earthquake Spectra, 28(2), pp. 595-619, 2012. https://doi.org/10.1193/1.4000004

[12] Singh, Y., Lang, D.H. \& Narasimha, D.S., Seismic risk assessment in hilly areas: case study of two cities in Indian Himalayas. Presented at the SECED 2015 Conference: Earthquake Risk and Engineering towards a Resilient World, Cambridge UK, 2015.

[13] Molina, S., Torres, Y., Benito, B., Navarro, M. \& Belizaire, D., Using the damage from 2010 Haiti earthquake for calibrating vulnerability models of typical structures in Port-auPrince (Haiti). Bulletin of Earthquake Engineering, 12(4), pp. 1459-1478, 2014. https://doi.org/10.1007/s10518-013-9563-z 
[14] Torres, Y., Molina, S., Martinez-Cuevas, S., Navarro, M., Martinez-Diaz, J. J., Benito, B., Galiana-Merino, J.J. \& Belizaire, D., A first approach to earthquake damage estimation in Haiti: advices to minimize the seismic risk. Bulletin of Earthquake Engineering, 14(1), pp. 39-58, 2016.

https://doi.org/10.1007/s10518-015-9813-3

[15] Jaiswal, K.S. \& Wald, D.J., Creating a global building inventory for earthquake loss assessment and risk management. U.S. Geological Survey (Open-File Report 20081160), available at: http://pubs.usgs.gov/of/2008/1160/. (accesed February 1, 2017).

[16] Brzev, S., Scawthorn, C., Charleson, A. \& Jaiswal, K., GEM basic building taxonomy, Version 1.0, GEM ontology and taxonomy global component project, available at: http://www.nexus.globalquakemodel.org/gemontology-taxonomy/posts/updated-gembasic-building-taxonomy-v1.0. (accesed February 1, 2017).

[17] Pitilakis, K. Franchin, P., Khazai, B., Wenzel, H. (eds.), SYNER-G: Systemic seismic vulnerability and risk assessment of complex urban, utility, lifeline systems and critical facilities, Springer-Verlag: Berlin and New York, 2014.

[18] International Code Council-ICC. International Building Code (IBC-2006), United States, 2006.

[19] CEN- European Committee for Standardization, EN 1998-1, Eurocode 8-design of structures for earthquake resistance, part 1: general rules, seismic actions and rules for buildings, Brussels, 1998.

[20] BIS - Bureau of Indian Standards, Indian standard - criteria for earthquake resistant design of structures, part 1-general provisions and buildings, Technical report, ICS 91.120.25, 2002.

[21] CNBS - Cuban National Bureau of Standards, Norma Cubana NC 46: 2013, Construcciones sismoresistentes - Requisitos básicos para el diseño y construcción, 1. Edición, Officina Nacional de Normalización (NC), Habana, Cuba, 2013.

[22] ICMS- Dipartamento de la Proteccione Civile, Indirizzi e criteri per la microzonacione sísmica, ed. Grupo di lavoro "ICMS". Conferen-za delle Regioni e delle Province autonome - Dipartimento della protezione civile, Roma, 3 vol. e Dvd, 2008.

[23] Molina, S., Lang, D.H., Meslem, A. \& Singh, Y., Topographic amplification effects towards their inclusion in ELE Studies (State-of-the-art report), Report no. 15-001, Alicante-Kjeller-Roorkee, 2015.

[24] Federal Emergency Management Agency- FEMA. Prestandard and commentary for the seismic rehabilitation of buildings. Technical report, Federal Emergency Management Agency (FEMA), Washington DC, FEMA 356, 2000.

[25] Federal Emergency Management Agency- FEMA. Improvement of nonlinear static seismic analysis procedures, Technical report, Applied Technology Council, California, USA. FEMA-440, 2005.

[26] Fajfar, P., Structural analysis in earthquake engineering. A breakthrough of simplified nonlinear methods, Presented at the 12th European Conference on Earthquake Engineering, London, paper 843, 2002.

[27] Dolsek, M. \& Fajfar, P., Inelastic spectra for infilled reinforced concrete frames. Earthquake Engineering and Structural Dynamics, 33, pp. 1395-1416, 2004. https://doi.org/10.1002/eqe.410 